\title{
Machining variables influence on the fatigue life of end-milled aluminium alloy
}

\author{
Sunday J. Ojolo* , Ifeoluwa J. Orisaleye, Nnaemeka Obiajulu \\ Dept. of Mechanical Engineering, University of Lagos, Akoka-Yaba, Lagos, Nigeria
}

Email address:

sojolo@unilag.edu.ng (S. J. Ojolo), orisaleyeifeolu@yahoo.com (I. J. Orisaleye), oj_nnaemeka@yahoo.com (N. Obiajulu)

\section{To cite this article:}

Sunday J. Ojolo, Ifeoluwa J. Orisaleye, Nnaemeka Obiajulu. Machining Variables Influence on the Fatigue Life of End-Milled Aluminium Alloy. International Journal of Materials Science and Applications. Vol. 3, No. 6, 2014, pp. 391-398. doi: 10.11648/j.ijmsa.20140306.27

\begin{abstract}
Machining involves the thermal, elastic and plastic deformations of the surface layer which result in strain hardening, structural changes and development of residual stresses. These cause surface irregularities which may increase the risk of fatigue failure of material during usage. This study involves the investigation of the influence of cutting speed, feed rate and tool geometry on the fatigue life of end-milled specimens of 2024-aluminium alloy using a design of experiment approach. The experimental design constructed was such that the specimens were subjected to different machining conditions. Data analysis was carried out with Relia Soft Office ${ }^{\mathrm{TM}} 7 \mathrm{DOE}++$ software and Analysis of Variance (ANOVA). The study showed that by decreasing the feed rate (from $60 \mathrm{~mm} / \mathrm{min}$ to $7 \mathrm{~mm} / \mathrm{min}$ ) and increasing the cutting speed (from $3.77 \mathrm{~m} / \mathrm{min}$ to $48.25 \mathrm{~m} / \mathrm{min}$ ) significantly resulted in a higher fatigue life (from $1.93 \times 10^{3}$ cycles to $2.53 \times 10^{3}$ cycles). Whereas, the rake angle had the least significant effect on the fatigue life, it was discovered that the feed rate was found to be the most influential factor.
\end{abstract}

Keywords: End-Milling, Machining Variables, Tool Geometry, Design of Experiments, Analysis of Mean, ANOVA

\section{Introduction}

Machining is an important and competitive alternative process for producing a wide range of mechanical components Milling is particularly a versatile and efficient machining process used in generating a wide variety of surfaces. During machining, however, the surface layer is subjected to elastic-plastic deformation and heating, which result in structural changes, strain hardening and residual stresses, while irregularities may appear, creating surface roughness. These affect some mechanical properties of the metal such as tensile and fatigue strengths [1]. During machining operations, improper machining conditions give rise to poor surface texture of the specimen, which when coupled with the cyclic loading leads to crack propagation and subsequently fatigue failure. Fatigue failures also result from geometrical or strain discontinuities, poor workmanship or improper manufacturing techniques. Residual stress on the machined surface is also known to influence the fatigue life of the component $[2,3]$.

The effect of machining and surface integrity on fatigue life has been reviewed by Novovic et al. [4]. They noted that there are disagreements in literature about the influence of surface roughness on fatigue life. It has been reported in most cases that fatigue life increases with decreasing surface roughness.
This effect diminishes for roughness parameter $R_{a}<0.1 \mu \mathrm{m}$. However, for roughness parameter $\left(\mathrm{R}_{\mathrm{a}}\right)$ between 2.5 and $5 \mu \mathrm{m}$, Koster [5] found that the residual stress is the most important factor on the fatigue life of structural alloys. This effect decreases with an increase in temperature due to the relaxation of residual stress. Lopes et al. [6] also stated that the fatigue limit of AISI 4140 steel decreases with increasing roughness parameters.

Sasahara [7] studied the effect of residual stress and surface hardness resulting from different cutting conditions on fatigue life of $0.45 \% \mathrm{C}$ steel. He noted that the affected layer is generated within the machined surface layer through the cutting process. Cutting conditions such as the nose radius of the tool, feed rate and shape of cutting edge at the finishing operation affect the residual stress, surface hardness, and surface roughness. It was also shown that such machined surface property could be controlled by the setting of the cutting conditions to some extent. The effect of the machining conditions on the fatigue life was investigated through a fatigue test using the specimen finished under various cutting conditions. The work showed that it is possible to obtain longer fatigue life for machined parts than the virgin material or the carefully finished material without affected layer, only by setting the proper cutting conditions. This was realized when the generated residual stress was 
small and the induced surface hardness was high. It was concluded that a longer fatigue life for the machined components can be obtained by applying such cutting conditions as a low feed rate, a small nose radius and a chamfered edge cutting tool.

Arola and Williams [8] found that the high-cycle fatigue life of machined specimens of AISI 4130 steel depends on the surface texture observing that the fatigue strength decreased with an increase in surface roughness from 2 to $6 \mu \mathrm{m}$. They noticed, however, that there was an increase in fatigue life with increasing surface roughness under low-cycle fatigue. It was also obsevered that the notch sensitivity of these machined specimens did not change significantly with surface roughness.

Huang and Ren [9] presented a study of the formation of surface roughness, residual stress and surface hardening produced by cutting and grinding. They compared the different effects of surface integrity on the high-cycle and low-cycle fatigue lives of the nickel-based superalloy $\mathrm{GH} 33 \mathrm{~A}$ at room temperature and at $550^{\circ} \mathrm{C}$. They concluded that, under the condition of low-cycle fatigue, surface roughness becomes the main factor and surface hardening has an unfavourable influence on the fatigue life, while the residual stress can be neglected because of its relaxation under the applied loads. They also noted that the influence of the integrity of the surface on the high-cycle fatigue life has a different mechanism from that on the low-cycle fatigue life.

Balkrishna and Yung [10], from their study on high speed face-milling of 7075-T6 aluminium alloy, using carbide and diamond cutters noted that higher cutting speeds result in higher efficiency, higher material removal rates and improved surface finish. They showed that for cutting speeds up to 152.4 $\mathrm{m} / \mathrm{min}$, the compressive nature of the residual stresses diminished. However, increasing the feed led to higher efficiency, higher material removal rates and better residual stresses, but at the expense of a poor surface finish. Also, increasing the depth of cut improved the material removal rate with a negative impact in terms of residual stresses and surface finish.

Itoga et al. [11] studied the effects of surface roughness on cracks initiation of Ni-Cr-Mo steel and stated that surface roughness was the most important influencing factor in short life regime. They observed that the fatigue life decreased with increasing surface roughness. Surface roughness, however, exerted very little or no influence on fatigue life in the long life regime because cracks nucleated at inclusions and grew inside the specimens.

It is clearly seen from past works that cutting speed, feed rate and tool geometry are variables that have a huge effect on fatigue life of metals. Determination of the relationship between these variables and fatigue life can help in choosing the optimum values for which fatigue failure can be substantially reduced. This will be particularly relevant to the end-milling process for which understanding has not been fully gained. In this study, the influence of machining variables such as cutting speed, feed rate and tool geometry (rake angle) on the fatigue life of end-milled specimens of 2024-aluminium alloy is investigated.

\section{Materials and Methods}

\subsection{Materials}

The materials and equipment used in carrying out this study include seventy-four (74) fatigue test samples from 2024-aluminium alloy of 5mm thickness, meter rule, vernier caliper, end milling cutters, side milling cutters, drilling machine, Avery 7305 plane bending fatigue testing machine, GOMU EF-1100 vertical milling machine. The aluminium sheets were purchased from the Owode Metal Market, Lagos State, Nigeria. The process parameters used in this study include:

i. End milling cutters of diameter $12 \mathrm{~mm}$ with rake angles of $30^{\circ}, 40^{\circ}$ and $45^{\circ}$

ii. Cutter spindle speeds of 100, 320, 580 and $1280 \mathrm{rpm}$

iii.Feed rates of 7, 15 and $60 \mathrm{~mm} / \mathrm{min}$.

iv. Depth of cut of $1 \mathrm{~mm}$

\subsection{Experimental Methods}

\subsubsection{Specimen Fabrication}

The aluminum sheets were cut into several pieces with dimensions $90 \times 30 \mathrm{~mm}$. The pieces were then machined according to the specimen shape and dimensions shown in Figure 1 using side milling to achieve the shape described. The drilling machine was used to drill the required holes (diameters of $7 \mathrm{~mm}$ each). The machined specimen being drilled is shown alongside the milled specimens in Figure 2.

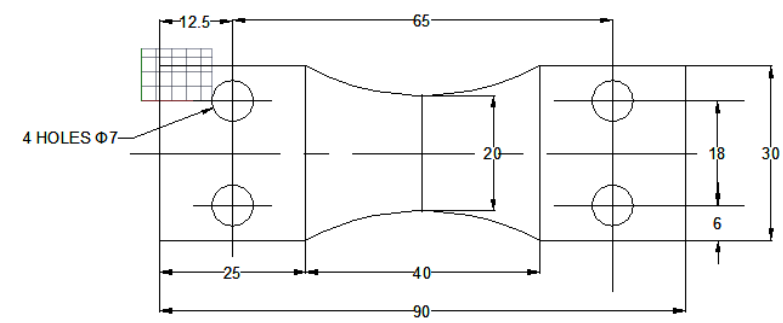

Figure 1. Fatigue test specimen

\subsubsection{End Milling Operation}

The specimens were subjected to several cutting conditions on the GOMU-EF1100 vertical milling machine, using the end milling cutters with rake angles of $30^{\circ}, 40^{\circ}$ and $45^{\circ}$. The cutter spindle speeds chosen for the machining operation were 100 , 320,580 and $1280 \mathrm{rpm}$ while feed rates were 7, 15 and 60 $\mathrm{mm} / \mathrm{min}$. A constant depth of cut of $1 \mathrm{~mm}$ was maintained throughout the machining operation. Only one face of all specimens was face-milled leading to a final thickness of $4 \mathrm{~mm}$. All specimens were machined according to a designed experiment shown in Table 1 with three cutting speeds.

\subsubsection{Fatigue Test}

Fatigue tests were carried out on each of the samples on the Avery Denison 7305 plane bending fatigue machine shown in Figure 3(a) and (b). Each of the specimens was mounted in position in the machine and the cycle counter was set to zero. 
The motor was switched on and the specimens were subjected to repeated cycle of plane bending until failure occurred. The number of cycles to failure was recorded. Fatigue tests were also carried out on the control samples which are specimens that were not machined. Figure 3(c) shows one of the failed specimens after the test.
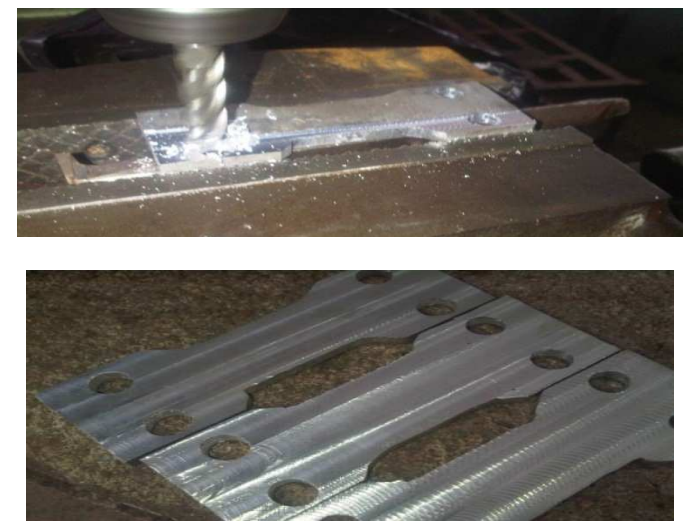

Figure 2 (a) and (b). Drilling holes into specimen to be subjected to end milling; Specimen which have been subjected to end milling
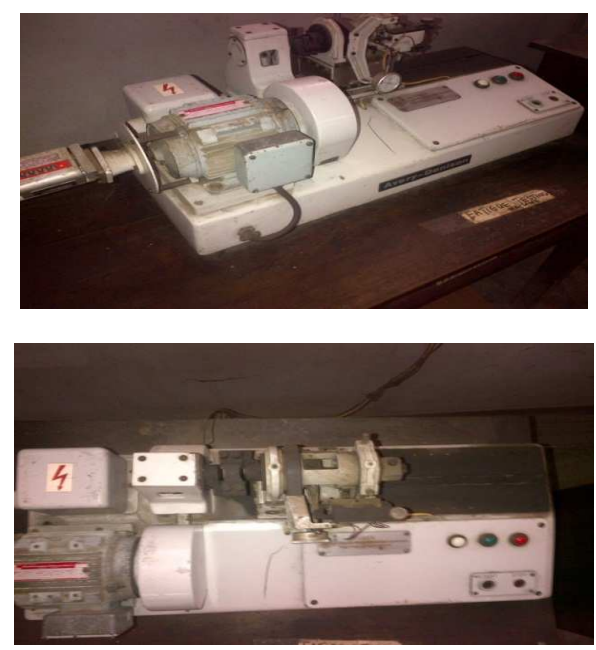

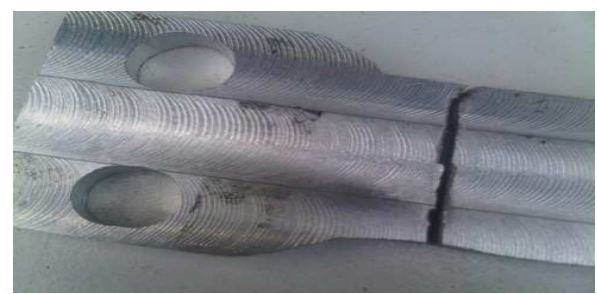

Figure 3(a) and (b). The Avery 7305 fatigue testing machine showing the specimen mounted (c) Failed fatigue specimen

\subsection{Data Analysis}

Based on the results obtained from the design of experiments, statistical and graphical analyses were carried out. The relative factor contributions of the parameters considered were obtained by analysis using the ReliaSoft Office $^{\mathrm{TM}} 7 \mathrm{DOE}++$ software. The analysis of means was done by calculating the means of the fatigue lives at various feed rates, tool rake angles and cutting speeds respectively. The plots gave a clear picture of the interaction of the variables. The main effect plot combines all curves from the term effect plot into one graph for the purpose of comparison to create a clear picture of the various interactions. A Pareto Chart was also used to establish both the individual and combined effect of the factors considered on the fatigue life of the specimens.

\section{Results and Discussions}

The results obtained from the experiment designed are presented in Table 1. Graphical presentations of the results are shown in Figures 4 to 6 presenting the variation of the fatigue life of each specimen for different rake angles with the cutting speeds and at different feed rates.

Table 1. Results obtained from the Design of Experiment

\begin{tabular}{|c|c|c|c|c|}
\hline Exp. No. & Rake angle $\left(^{\circ}\right)$ & Feed rate $(\mathrm{mm} / \mathrm{min})$ & Cutting speed (rpm ) & Number of cycles to failure $(x 1000)$ \\
\hline 1 & 30 & 7 & 100 & 2.53 \\
\hline 2 & 30 & 7 & 320 & 2.96 \\
\hline 3 & 30 & 7 & 580 & 3.24 \\
\hline 4 & 30 & 7 & 1280 & 3.32 \\
\hline 5 & 30 & 15 & 100 & 2.19 \\
\hline 6 & 30 & 15 & 320 & 2.23 \\
\hline 7 & 30 & 15 & 580 & 2.42 \\
\hline 8 & 30 & 15 & 1280 & 2.51 \\
\hline 9 & 30 & 60 & 100 & 0.83 \\
\hline 10 & 30 & 60 & 320 & 0.89 \\
\hline 11 & 30 & 60 & 580 & 1.43 \\
\hline 12 & 30 & 60 & 1280 & 1.93 \\
\hline 13 & 40 & 7 & 100 & 2.6 \\
\hline 14 & 40 & 7 & 320 & 3.01 \\
\hline 15 & 40 & 7 & 580 & 3.4 \\
\hline 16 & 40 & 7 & 1280 & 3.42 \\
\hline
\end{tabular}




\begin{tabular}{lllll}
\hline Exp. No. & Rake angle $\left(^{\circ}\right)$ & Feed rate $(\mathbf{m m} / \mathbf{m i n})$ & Cutting speed $(\mathbf{r p m})$ & Number of cycles to failure $(\mathbf{x 1 0 0 0})$ \\
\hline 17 & 40 & 15 & 100 & 2.3 \\
18 & 40 & 15 & 320 & 2.38 \\
19 & 40 & 15 & 580 & 2.49 \\
20 & 40 & 60 & 1280 & 2.53 \\
21 & 40 & 60 & 100 & 0.96 \\
22 & 40 & 60 & 320 & 1.34 \\
23 & 40 & 60 & 580 & 1.46 \\
24 & 40 & 7 & 1280 & 1.99 \\
25 & 45 & 7 & 100 & 2.67 \\
26 & 45 & 7 & 320 & 3.15 \\
27 & 45 & 7 & 580 & 3.49 \\
28 & 45 & 15 & 1280 & 3.6 \\
29 & 45 & 15 & 100 & 2.33 \\
30 & 45 & 15 & 320 & 2.45 \\
31 & 45 & 15 & 580 & 2.52 \\
32 & 45 & 60 & 1280 & 2.72 \\
33 & 45 & 60 & 100 & 1.00 \\
34 & 45 & 60 & 320 & 1.36 \\
35 & 45 & 60 & 580 & 1.83 \\
36 & 45 & 1280 & 2.12 \\
\hline
\end{tabular}

\subsection{Effect of Cutting Speed}

From Table 1, it was observed that the fatigue life increased (from $2.67 \times 10^{3}$ to $3.6 \times 10^{3}$ cycles to failue) as the cutting speed increased from $100 \mathrm{rpm}(0.06 \mathrm{~m} / \mathrm{s})$ to $1280 \mathrm{rpm}(0.8 \mathrm{~m} / \mathrm{s})$. There was a decrease in surface roughness of the specimen at higher cutting speeds which might have resulted from the thermal softening effect due to accumulated heat which caused a temperature rise in the machining zone. Reduction in surface roughness implies that there will be fewer points of fatigue crack initiation on the specimen and hence lower probability of crack propagation and lengthen the fatigue life. Therefore, the reduction in surface roughness might have been the reason for the increased fatigue life. Mohammed et al. [12] have also observed that cutting speed improves surface finish noting that machinability is increased at higher cutting speed and leading to reduced built up edge. Rech and Moisan [13] obtained a different situation from their analysis by stating that the average surface roughness increases with both cutting speeds and feed rates.

\subsection{Effect of Feed Rate}

As observed from Figures 4-6, for a constant value of cutting speed, but with an increase in feed rate from $7 \mathrm{~mm} / \mathrm{min}$ to 60 $\mathrm{mm} / \mathrm{min}$, there was a decrease in fatigue life (from $3.15 \times 10^{3}$ to $2.12 \times 10^{3}$ cycles to failure) of the aluminum specimens. A fine surface texture was observed at low feed rates but a coarse texture was produced at higher feed rates. This implies that increase in feed rate significantly increased the surface roughness of the specimen. A possible reason is that at higher feed rates the teeth of the end mill cutter did not perfectly swipe through the entire surface of the machined zone to create a very smooth surface, which is in similar to the result obtained by Mohammed et al. [12]. Furthermore, at higher feed rate, the friction between the work material and cutting tool was higher due to larger cross sectional area in the deformation zone thereby increasing the surface roughness. As discussed earlier, the increased surface roughness could have led to development of more locations of fatigue crack initiation and propagation and significantly reduced the fatigue life of the specimens. Sasahara [7], Thamma [14], Rech and Moisan [13] reported similar results on the improvement of the surface finish with a decrease in feed rate.

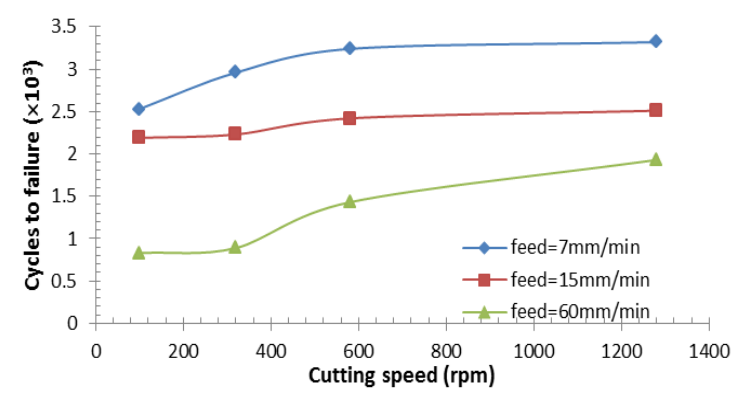

Figure 4. Effect of cutting speed and feed on fatigue life at constant rake angle of $30^{\circ}$

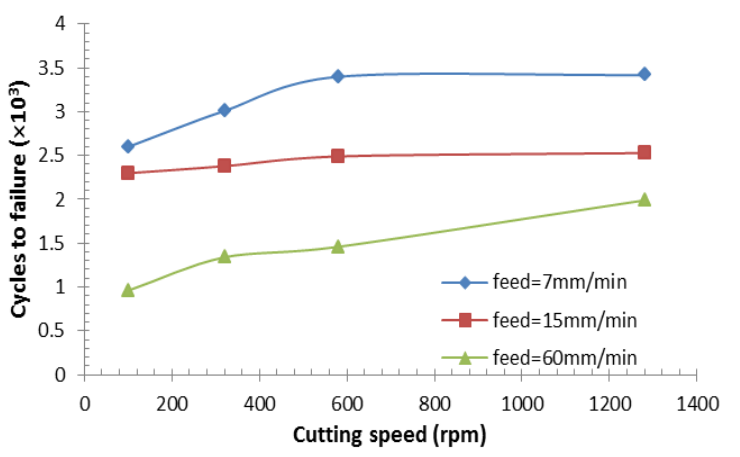

Figure 5. Effect of cutting speed and feed on fatigue life at constant rake angle of $40^{\circ}$ 


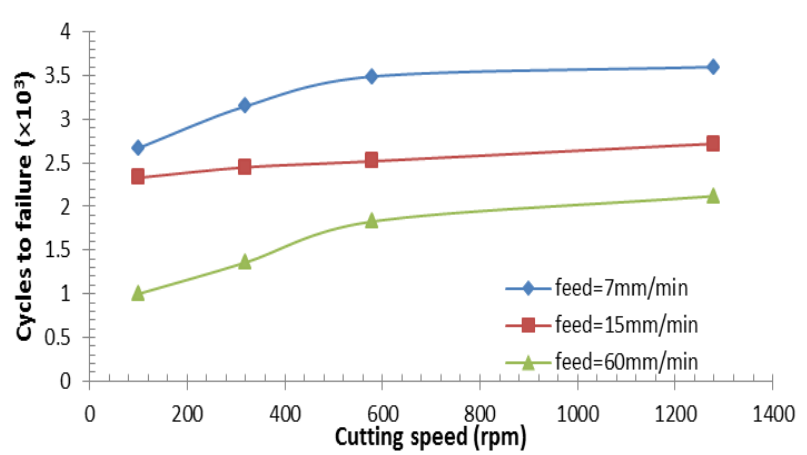

Figure 6. Effect of cutting speed and feed on fatigue life of the at constant rake angle of $45^{\circ}$

\subsection{Effect of Rake Angle}

It was observed that an increase in rake angle of the milling cutter from $30^{\circ}$ to $45^{\circ}$ resulted in a better surface finish but slightly increased the fatigue life (from $2.53 \times 10^{3}$ to $3.49 \times 10^{3}$ cycles to failure) of the specimens (Figures 4-6). There was increase in the length of continuous chips produced at higher rake angles of $40^{\circ}$ and $45^{\circ}$. Davim [15] and Feng [16] have noted that rake angle is one of the tool geometry which significantly influences the surface roughness.

\subsection{Data Analysis}

\subsubsection{Analysis of Means}

The relative factor contributions of the parameters considered were obtained by analysis using the ReliaSoft Office ${ }^{T M} 7 \mathrm{DOE}++$ software. The analysis of means was obtained by calculating the means of the fatigue lives at various feed rates, tool rake angles and cutting speeds respectively. The main effect plot combines all curves from the term effect plot into one graph such that a better picture of the interactions is obtained.

The analysis of means showed that the feed rate had the greatest effect on the fatigue life as shown by a wider range of values and a very steep slope of the fitted means curve shown on the term effect plot in Figure 7 and main effect plot in Figure 8 . The cutting speed of the end mill cutter has the second most profound effect while the rake angle has the least effect on the fatigue life as shown in the figures.

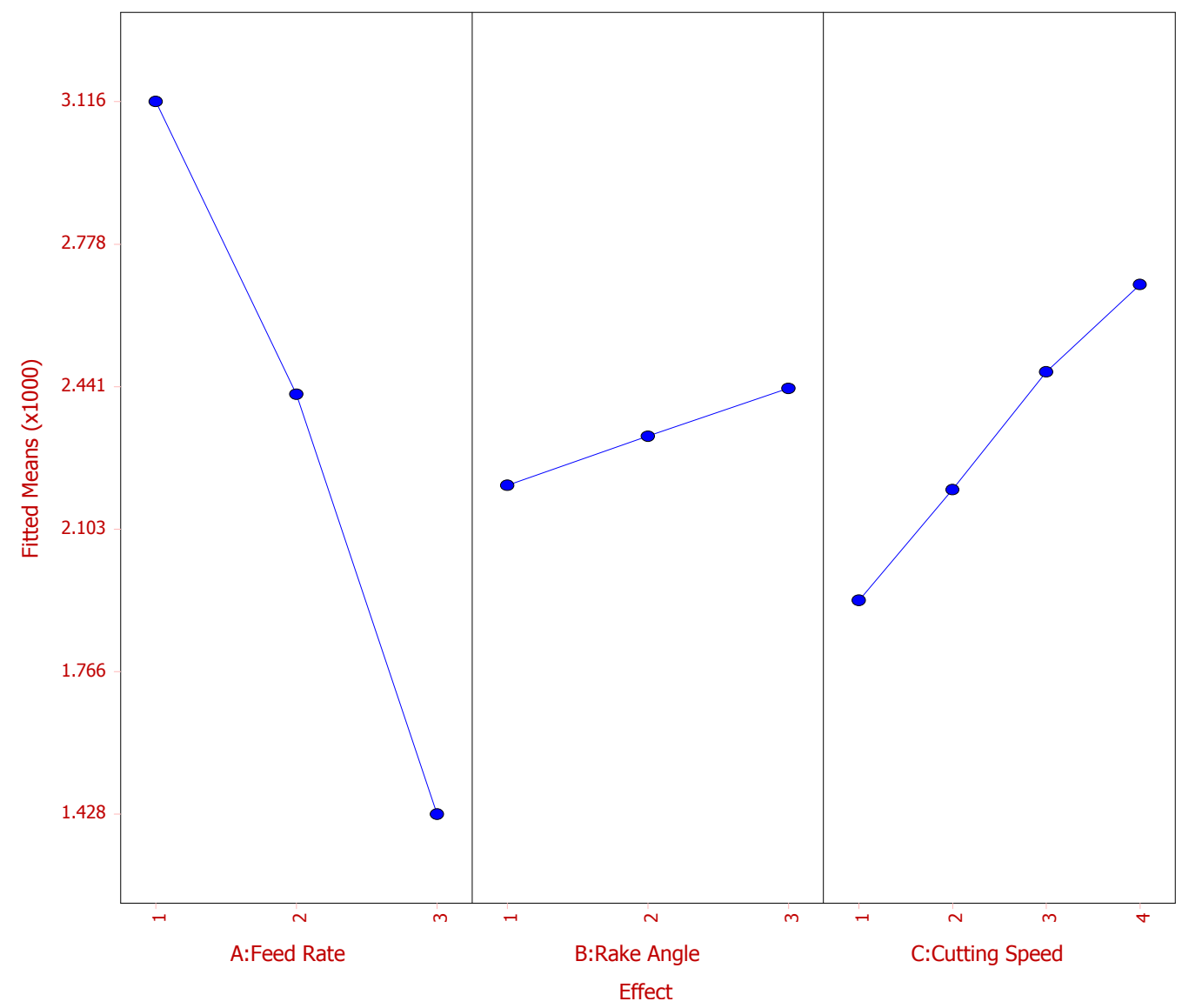

Figure 7. Term effect plot of cutting variables 


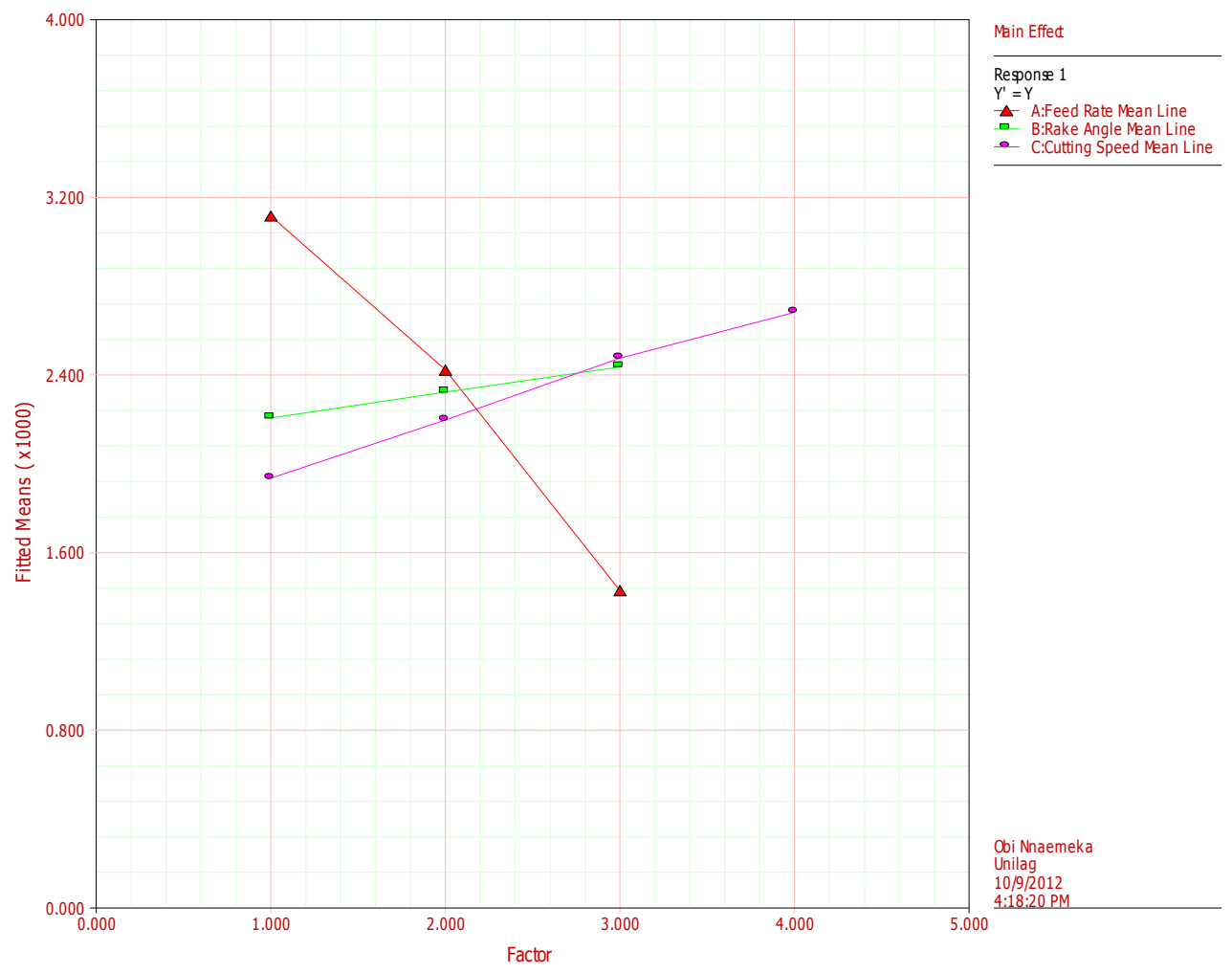

Figure 8. Main effect plot of cutting variables

Figure 9 shows an interaction matrix which establishes all possible graphical relationship between the variables represented (cutting speed, feed rate and rake angle). As observed, the curves in the interaction matrix graphs are mostly parallel. This shows that there is minimal interaction between the cutting speed, feed rate and rake angle implying that all the effects of the individual variables are independent of each other.

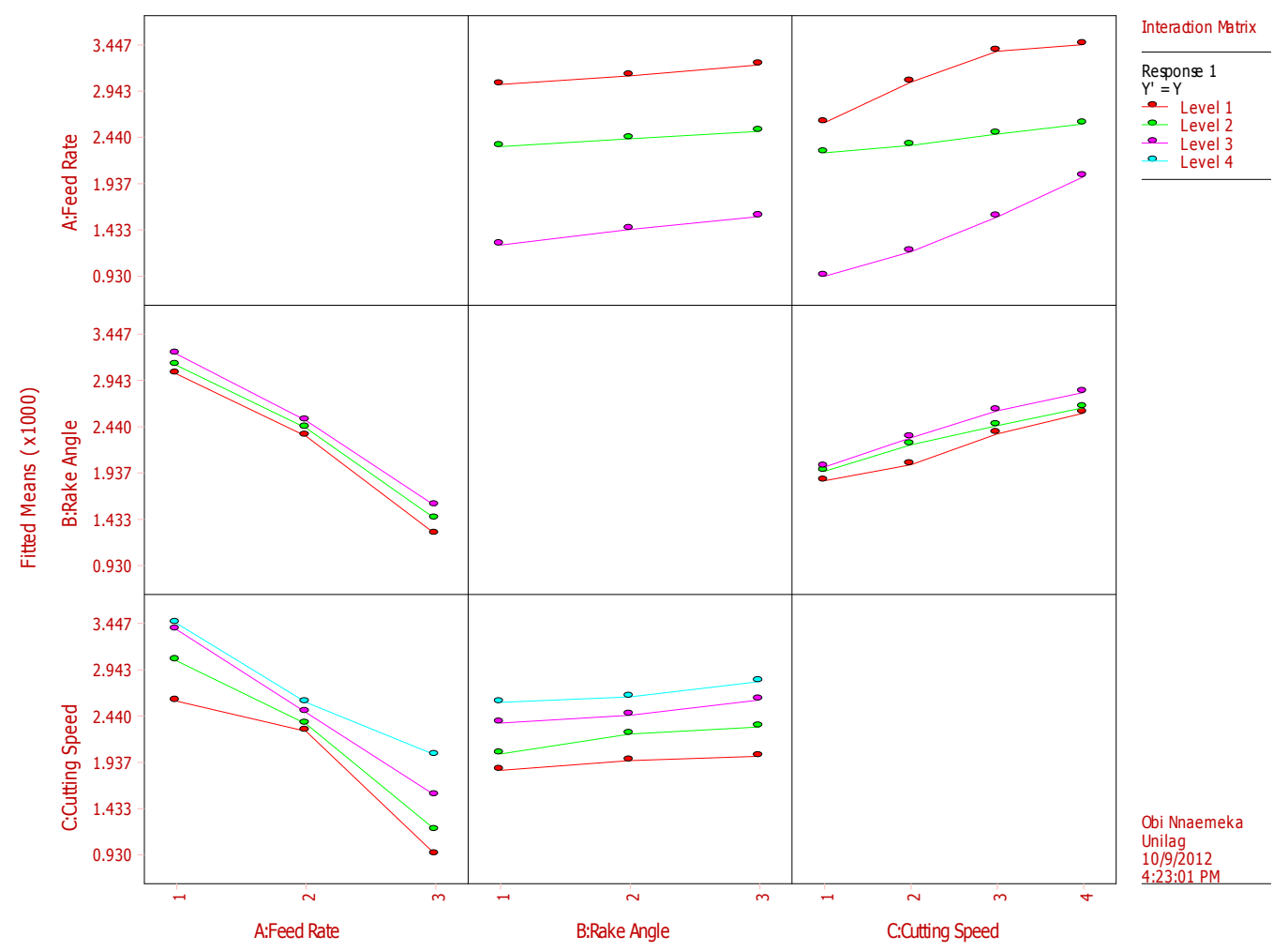

Figure 9. Interaction matrix of cutting variables 
The Pareto chart shown in Figure 10 establishes both the individual and combined effect of the factors considered on the fatigue life of the specimens. As seen from Figure 9, the feed rate is denoted by $\mathrm{A}$, while $\mathrm{B}$ and $\mathrm{C}$ denote rake angle and cutting speed respectively. The numbers in the square brackets denote their respective levels, also shown in Figure 9.

It is seen that the significant contributions, with effects above the critical value of 0.168 , consist mainly of the single effects of feed rate and cutting speed or their combined effects. It is also observed that the lowest values for feed rate and cutting speed (A[1] and $\mathrm{C}[1])$ have the most significant effect on the fatigue life and consequently surface roughness of the test specimens. This is in agreement with Kumar et al. [17] result that the feed rate is the most significant machining parameter for surface roughness, followed by depth of cut and cutting speed. C[4] was not represented in the Pareto chart because at very high speeds, the relative change in surface roughness, and hence fatigue life, becomes statistically insignificant. This can also be established by a look at the Figures 4 to 6, where an increase in the cutting speed from 580 rpm to $1280 \mathrm{rpm}$ yields very small change in the fatigue life of the specimens. Rake angle (B) and the three-factor combination had little or no significant effect on the fatigue life. This analysis shows that the surface roughness, and hence the fatigue life, of metals that are subjected to machining operations are influenced majorly by the feed rate-cutting speed combination. For optimum fatigue life, these values should be carefully selected during machining of metals.

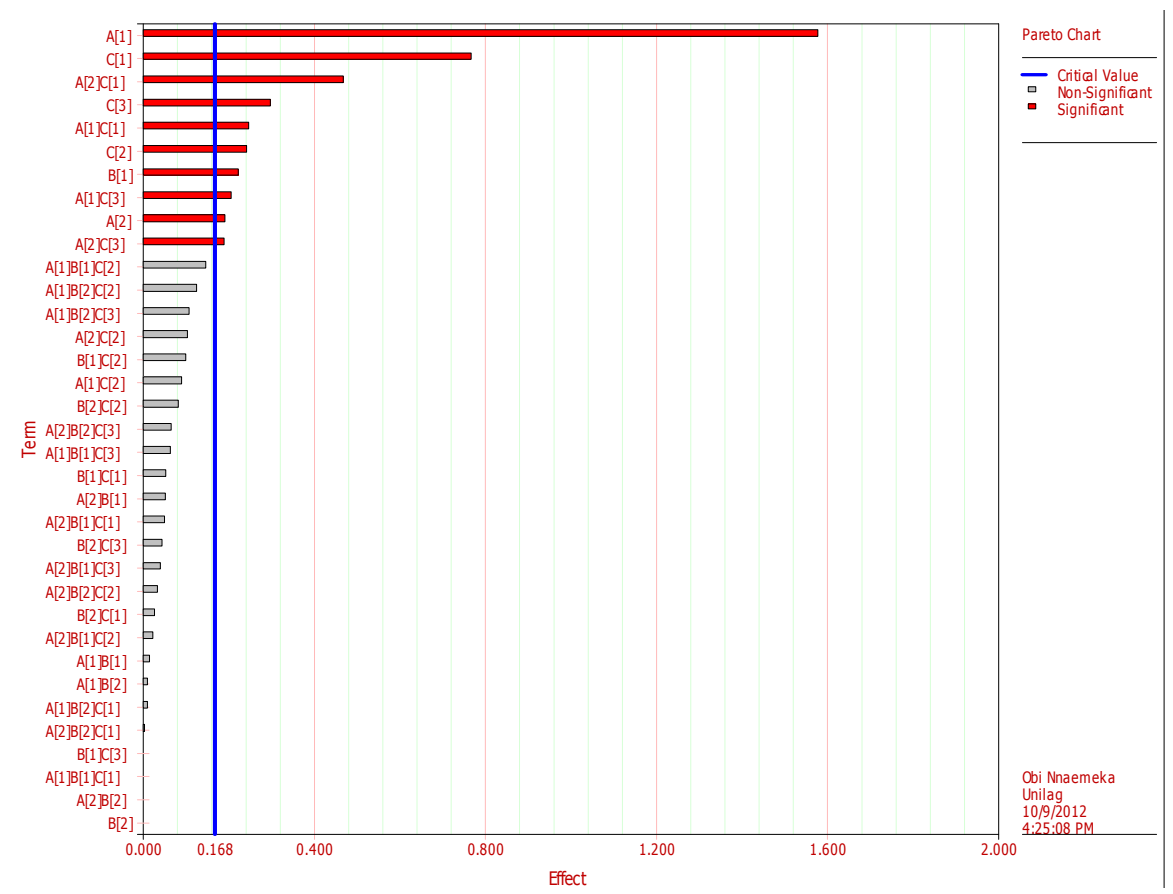

Figure 10. Pareto Chart showing the individual and combined effects of variables on fatigue life of specimens

\subsubsection{Analysis of Variance}

Further, ANOVA was performed to investigate the statistical significance of the variables on the fatigue life. This analysis takes into account the amount of information used to obtain the degrees of freedom and provides a more valid basis for comparison. The ANOVA table presented in Table 2 is the results obtained from the analysis of means. It shows that the effects of two-way and three-way interactions on the performance characteristics, that is fatigue life, are not very profound and the main effects give the main source variations.
This is indicated by the column of the sum of squares on the ANOVA table which is an indication of the variances of the various source variations. The two and three-way interactions gave a far lower source variation. The main effects, which are cutting speed, feed rate and rake angle, gave a sum of squares of 20.4576 which is about $96.4 \%$ contribution to the performance characteristic. This is further validated by a higher value of 2.9225 on the mean ssquares column which is obtained by dividing the sum of squares column by the degrees of freedom.

Table 2. ANOVA Table for contribution of each variable to the fatigue life

\begin{tabular}{llllll}
\hline Source of Variation & Degrees of Freedom & Sum of Squares [Partial] & Mean Squares [Partial] & F Ratio & P Value \\
\hline Model & 35 & 21.2264 & 0.6065 & - & - \\
Main Effects & 7 & 20.4576 & 2.9225 & - & - \\
2-Way Interaction & 16 & 0.6987 & 0.0437 & - & - \\
3-Way Interaction & 12 & 0.0701 & 0.0058 & - & - \\
Residual & 0 & & & \\
Total & 35 & 21.2264 & & \\
\hline
\end{tabular}




\section{Conclusions}

This study investigated the influence of cutting speed, feed rate and tool geometry on the fatigue life of end-milled specimens of 2024-aluminium alloy using a design of experiment approach. The experimental design constructed was such that the specimens were subjected to different machining conditions with the variation of cutting speed, feed rate and rake angle and the fatigue life of each specimen determined thereafter. The results showed that the fatigue life of the specimens increased (from $2.67 \times 10^{3}$ to $3.6 \times 10^{3}$ cycles to failue) with increasing cutting speed (from $3.77 \mathrm{~m} / \mathrm{min}$ to $48.25 \mathrm{~m} / \mathrm{min}$ ) and with decreasing feed rate (from $7 \mathrm{~mm} / \mathrm{min}$ to $60 \mathrm{~mm} / \mathrm{min}$ ). Analysis of means carried out with ReliaSoft Office $^{\mathrm{TM}} 7 \mathrm{DOE}++$ software and Analysis of Variance (ANOVA) also showed that by decreasing the feed rate from $60 \mathrm{~mm} / \mathrm{min}$ to $7 \mathrm{~mm} / \mathrm{min}$ was significant resulting in a higher fatigue life of the specimens (from $2.12 \times 10^{3}$ to $3.15 \times 10^{3}$ cycles to failure). Increasing the cutting speed of the cutter from 100 $\mathrm{rpm}(0.06 \mathrm{~m} / \mathrm{s})$ to $1280 \mathrm{rpm}(0.8 \mathrm{~m} / \mathrm{s})$ also significantly affected the fatigue life of the 2024-aluminium alloy specimens used positively. However, when the rake angle was increased from $30^{\circ}$ to $45^{\circ}$, the effect on the specimens was least significant. The feed rate was found to be the most influential factor affecting fatigue life. It is shown that the fatigue life of metal components decrease with increasing feed rate and a decrease in cutting speed with feed rate having the most influence. This is very relevant to the design of components which will be subjected to repeated cycles of loading and unloading and are highly susceptible to fatigue failure. It is hence very obvious that to produce components with optimum fatigue life a low feed rate and a reasonably high cutting speed should be maintained in the cutting process. Rake angle has the least effect on fatigue life as increasing the rake angle slightly increases the surface roughness. Therefore the rake angle of the cutter used in the operation should be carefully chosen to a value that is not too high that it could produce non-uniform deformation and hence increase the surface roughness instead of decreasing it.

\section{References}

[1] P.G. Benardos, and G.C. Vosniakos, "Predicting Surface Roughness in Machining: A review", International Journal of Machine Tools \& Manufacture, 43(8) (2003), 833-844.

[2] J.D. Thiele, S.N. Melkote, R.A. Peascoe, and T.R. Watkins, "Effect of cutting edge geometry and workpiece hardness on surface residual stresses in finish turning of AISI 52100 steel", J. Manuf. Sci. Eng., 122(4) (2000), 642-649.

[3] Yukitaka, M. (2002), Metal Fatigue: Effects of small defects and non-metallic inclusions (Kyushu University, Japan), Elsevier, 2002.
[4] D. Novovic, R.C. Dewes, D.K. Aspinwal, W. Voice, and P. Bowen, (2004) "The Effect of Machined Topography and Integrity on Fatigue Life", International Journal of Machine Tools \&Manufacture, 44 (2-3) (2004), 125-134.

[5] W. Koster, (1991). "Effect of Residual Stress on Fatigue of Structural Alloys", Proceedings of the Third International Conference, ASM International, Indianapolis, Indiana, USA, (1991), 19.

[6] K.S.S. Lopes, W.F. Sales, and E.S. Palma, (2008) "Influence of machining parameters on fatigue endurance limit of AISI 4140 steel", Journal of the Brazillian Society of Mechanical Science \& Engineering, 30 (1) (2008), 77-83.

[7] H. Sasahara, "The effect on fatigue life of residual stress and surface hardness resulting from different cutting conditions of $0.45 \% \mathrm{C}$ steel", International Journal of Machine Tools and Manufacture, 45 (2) (2005), 131-136.

[8] D. Arola, and C.L. Williams, "Estimating the Fatigue Concentration Factor of Machined Surfaces", International Journal of Fatigue, 24 (9), 923-930.

[9] Q. Huang, and J.X. Ren, "Surface integrating and its effects on the fatigue life of the nickel-based superalloy GH33A", International Journal of Fatigue, 13(14) (1991), 322-326

[10] R. Balkrishna and C.S. Yung, "Analysis on high-speed face-milling of 7075-T aluminium using carbide and diamond cutters", International Journal of Machine Tools \& Manufacture, 41(2001),1763-1781.

[11] H. Itoga, K.Tokaji, M. Nakajima, and H.H. Ko, "Effect of Surface Roughness on Step- Wise S-N Characteristic in High Strength Steel”, Int. J. of Fatigue, 25 (5) (2003), 379-385.

[12] T. Mohammed, S. Montasser, and B. Joachim, "A Study of the Machining Parameters on the Surface Roughness in the End-Milling Process", Jordan Journal of Mechanical and Industrial Engineering, 1(2007), 1-5.

[13] J. Rech, and A. Moisan, "Surface Integrity in Finish Hard Turning of Case Hardened Steels, International Journal of Machine Tools \& Manufacture, (43) (5) (2003), 543-550.

[14] Thamma, "Comparison between multiple regression models to study effect of turning parameters on the surface roughness", Proceedings of the 2008 IAJC-IJME International Conference, Paper 133, Eng. (2008),103.

[15] J.P. Davim, "A Note on the Determination of Optimal Cutting Conditions for Surface Finish obtained in Turning using Design of Experiments", Journal of Materials Processing Technology, 116 (2001), 305-308.

[16] C-X. Feng, "An Experimental Study of the Impact of Turning Parameters on Surface Roughness", Proc. of the 2001 Industrial Engineering Research Conference, Institute of Industrial Engineers, (2001), 1-6.

[17] V.S.S. Kumar, C. Ezilarasan, and S.S. Kumaran, "Experimental investigation and optimization of cutting parameters in machining of Ti6Al4V Alloy by an MT-CVD insert", Journal of the Institution of Engineers (India), 94 (2) (2013), 155-163. 